\title{
5th Generation Wi-Fi
}

\author{
Shatha Ghazal ${ }^{1}$, Raina S Alkhlailah ${ }^{2}$ \\ Al- Balqa' Applied University (BAU) ${ }^{1,2}$
}

\begin{abstract}
Technology is evolving rapidly for making things easier. Due to innovative ideas at the customer and manufacturers level, new networking methods are introduced. Nowadays, these networking methods are concentrating on wireless technology (wi-fi) where it is the most acceptable and flexible one. It became popular for all, which wireless communications standards continue to evolve, to provide ever-increasing data throughput capabilities. Today, two of the hottest wireless standards are IEEE 802.11ac in wireless-local-area-network (WLAN) products and 3GPP LTE-Advanced in cellular communications. IEEE $802.11 \mathrm{ac}$ is the new draft standard for Gigabit wifi. IEEE 802.11ac promises data rates of up to $1.73 \mathrm{Gbps}$ between an access point and a wireless client. In this paper, we'll take a basic knowledge about IEEE 802.11ac. More specifically, we'll look at how features such as Video Streaming and Data Syncing and Backing Up. Finally, we'll look technical detail and its application.
\end{abstract}

Keywords: Wi-Fi, LTE, IEEE Standard, SS Id.

\section{INTRODUCTION}

IT STANDS as perhaps the signal success of the computer industry in the last few years, a rare bright spot in a bubble-battered market: Wi-Fi, the short-range wireless broadband technology. Tens of millions of Wi-Fi devices are sold every year, including the majority of laptop computers. Homes, offices, colleges and schools around the world have installed Wi-Fi equipment to blanket their premises with wireless access to the internet. Wi-Fi access is available in a growing number of coffee-shops, airports and hotels too. Yet merely five years ago wireless networking was a niche technology. How did Wi-Fi get started, and become so successful, in the depths of a downturn?

Wi-Fi seems even more remarkable when you look at its provenance: it was, in effect, spawned by an American government agency from an area of radio spectrum widely referred to as "the garbage bands". Technology entrepreneurs generally prefer governments to stay out of their way: funding basic research, perhaps, and then buying finished products when they emerge on the market. But in the case of Wi-Fi, the government seems actively to have guided innovation.

"Wi-Fi is a creature of regulation, created more by lawyers than by engineers," asserts Mitchell Lazarus, an expert in telecoms regulation at Fletcher, Heald \& Hildreth, a law firm based in Arlington, Virginia. As a lawyer, Mr Lazarus might be expected to say that. But he was also educated as an electrical engineer - and besides, the facts seem to bear him out.

Nowadays, wireless network is one of the essential phenomena that we deal with every moment in our lives. The use of wireless network had started in pcs and Laptops to provide flexibility towards connection location and reached to the level of interconnection of all of our devices (mobile phones, notepads, ipods, play consoles even tvs). The situation is now very different.

\section{HISTORY OF WI-FI}

The invention of Wi-Fi was found fifteen years earlier where the purpose of it was to provide scanning facilities for warehouse, and PC wireless connection to small LAN within an office space within the limit of $1 \mathrm{Mbps}$ and $2 \mathrm{Mbps}$ under the standard of IEE802.11, the same was known as the 1st generation. Two years later, the data rate for the same had been increased to $11 \mathrm{Mbps}$, which was known under the 2nd generation, which was known as 2nd generation (IEEE801.11b), the same popularly used for e-mail applications. Third generation Wi-Fi was introduced in 2002 with a data rate of 54Mbps (IEEE801.11 g/a) which was called the 3rd generation of Wi-Fi. The same was widely used for rich-data web experience. 4th generation was introduced in the year of 2007 under the standard IEEE $802.11 \mathrm{n}$ providing a data rate $600 \mathrm{Mbps}$ (on average and most common to be $150 \mathrm{Mbps})$. The same had provided medium resolution video streaming. Due to the high demand of use to the Wi-Fi technology, through multiple devices inside a single home, the 5th generation was developed to cover the extreme users demand in regard of full web accessibility featuring full resolution video streaming. The data rate offered is up to $3.6 \mathrm{Gbps}$ and the governing standard known as IEEE802.11ac.

Figure one below illustrates the time line evolution for the Wi-Fi technology. The typical Wi-Fi setup contains one or more Access Points (aps) and one or more clients. An AP broadcasts its SSID (Service Set Identifier, Network name) via packets that are called beacons, which are broadcasted every $100 \mathrm{~ms}$. The beacons are transmitted at $1 \mathrm{Mbps}$, and are relatively short and therefore are not of influence on performance. Since $1 \mathrm{Mbps}$ is the lowest rate of Wi-Fi it assures that the client who receives the beacon can communicate at least $1 \mathrm{Mbps}$. Based on the settings (i.e. The SSID), the client may decide whether to connect to an AP. In addition, the firmware running on the client Wi-Fi card is of influence. Say two AP's of the same SSID are in range of the client, the firmware may decide based on signal strength 
Vol. 5, Issue 8, August 2016

(Signal-to-noise ratio) to which of the two AP's it will future wireless cards will be more and more controlled by connect. The Wi-Fi standard leaves connection criteria and the operating system. Microsoft's newest feature called roaming totally open to the client. This is strength of Wi-Fi, softmac will take over from on-board firmware. Having but also means that one wireless adapter may perform said this, roaming criteria will be totally controlled by the substantially better than the other.

operating system. Wi-Fi transmits in the air, it has the same Since Windows XP there is a feature called zero properties as a non-switched ethernet network. Even configuration which makes the user show any network collisions can therefore appear like in non-switched available and let the end user connect to it on the fly. In the ethernet LAN's.

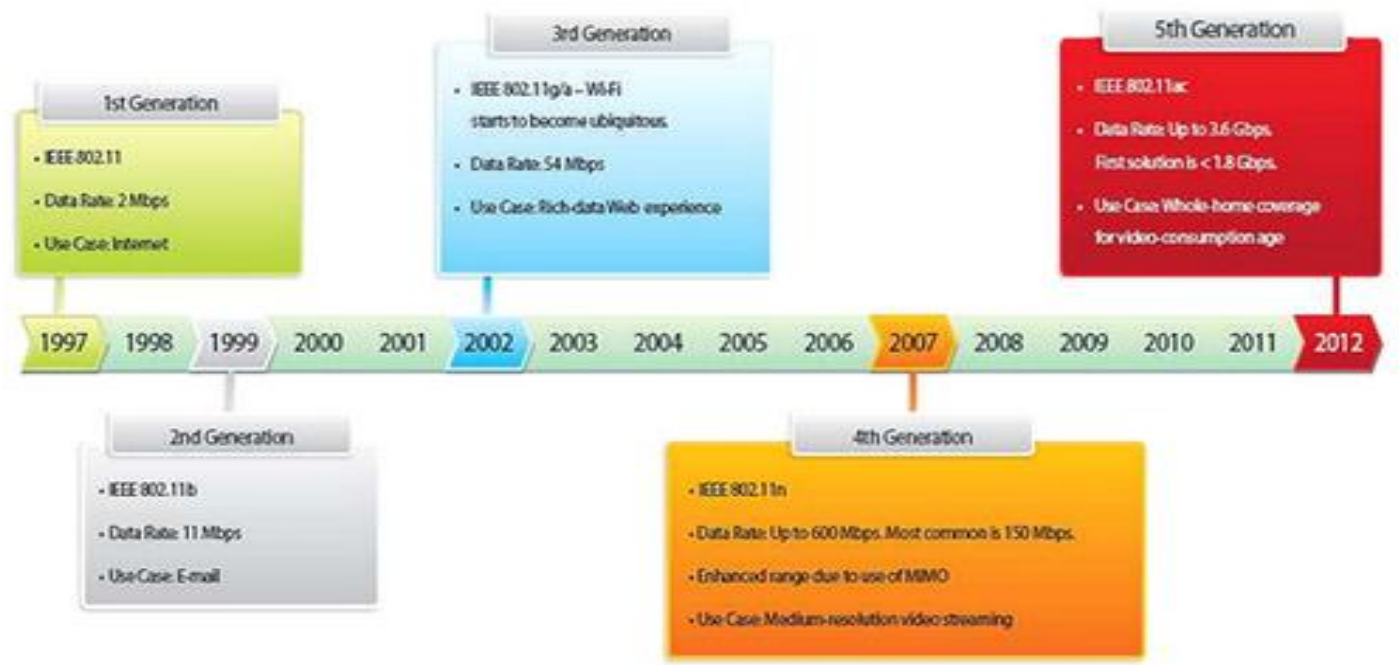

Figure (1): Wi-Fi time line

Wi-Fi offers many advantages for the communication systems which some of them are:

- Unlike packet radio systems, Wi-Fi uses unlicensed radio spectrum and does not require regulatory approval for individual deployers.

- Allows lans to be deployed without cabling, potentially reducing the costs of network deployment and expansion. Spaces where cables cannot be run, such as outdoor areas and historical buildings, can host wireless lans.

- Wi-Fi products are widely available in the market. Different brands of access points and client network interfaces are interoperable at a basic level of service.
- Competition amongst vendors has lowered prices considerably since their inception.

- Wi-Fi networks support roaming, in which a mobile client station such as a laptop computer can move from one access point to another as the user moves around a building or area.

- Many access points and network interfaces support various degrees of encryption to protect traffic from interception.

- Wi-Fi is a global set of standards. Unlike cellular carriers, the same Wi-Fi client works in different countries around the world.

- Table (1) Below illustrates the features development for all type of Wi-Fi generations.

\begin{tabular}{|c|c|c|c|c|c|}
\hline \multicolumn{6}{|c|}{ III COMPARISON OF ALL GENERATIONS OF MOBILE TECHNOLOGIES [s]- } \\
\hline $\begin{array}{c}\text { Technology } \rightarrow \\
\text { Features } \downarrow\end{array}$ & 16 & 26 & 36 & 46 & sc \\
\hline Stare Deptoy merat & $1970-1950$ & $1990-2004$ & $2004-2010$ & Now & $\begin{array}{l}\text { Sosen (probuably } \\
20020 \text { ) }\end{array}$ \\
\hline Data Bandwiath & 2 atps & 6tabtops & 230 tos & 1 ceps & Highter than $1 \mathrm{Gbps}$ \\
\hline Techaologs & $\begin{array}{l}\text { Analog Cellubler } \\
\text { Tectinotogy }\end{array}$ & 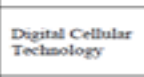 & $\begin{array}{l}\text { CDMA 2000 } \\
\text { (18RTI, } \\
\text { EVDO', } \\
\text { UMTS, EDGE }\end{array}$ & $\begin{array}{l}\text { WhMax LTE } \\
\text { Wh-Fi }\end{array}$ & wwwW(coening soon) \\
\hline Service & $\begin{array}{l}\text { Motule Teleptony } \\
\text { (Voce) }\end{array}$ & $\begin{array}{l}\text { Dagital vooce, } \\
\text { SMas, Higher } \\
\text { compiny } \\
\text { packetized data }\end{array}$ & $\begin{array}{l}\text { Integrated ligeh } \\
\text { quality sadto } \\
\text { video and dinta }\end{array}$ & $\begin{array}{l}\text { Dynamiec Infoermatioa } \\
\text { scesss, Weazable } \\
\text { devsces }\end{array}$ & 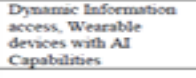 \\
\hline Mutriplesing & FDMA & IDMA CDMA & CDMA & cDase & CDMA \\
\hline Switching & Cincuit & Circum, Paxket & Packet & All Packet & All Packet \\
\hline Core Network & PSTN & PSTN & Packet N/w & Deternet & Intersone \\
\hline
\end{tabular}




\section{IEEE 802.11AC - THE 5TH GENERATION}

5G Wi-Fi offers providing higher capacity and capability for all users to view and stream high resolution videos. Also, due to the high dependability of users to use the internet and the necessity to be able in connecting multiple devices at the same time, $5 \mathrm{G} \mathrm{Wi-Fi} \mathrm{featuring} \mathrm{the} \mathrm{same} \mathrm{with}$ the maximum speed. 5G Wi-Fi overcomes the problems in the earlier versions of $\mathrm{Wi}-\mathrm{Fi}$ related to slow and discontinued connection for data (especially video streaming).

5G Wi-Fi provides higher speed which will lead to lower download time. The same will improve battery life time for smart phones and Laptops.

\section{FEATURES OF IEEE 802.11AC}

\section{-Video Streaming}

Despite the fact that the Laptops were invented to replace the use of desktop pcs, nowadays, the same (along with smart phones) are used for specific use which is related to video entertainment. These devices are replacement for TV. Accordingly, higher bandwidth and data rates are provided with $5 \mathrm{G}$ Wi-Fi to meet the demand.

\section{-Data synchronization and backup}

Every one now are relaying on his PC as a central hub for data storage and backup which might be available at our smart phones. Visa versa, we might require to upload or copy some data from our pcs (such as movies and music) prior travel or leave of our house. Such process might require a lot of time which might be reduced by using the new technology of $5 \mathrm{G} \mathrm{Wi-Fi.}$

\section{ADVANTAGES OF 5G Wi-Fi}

1. $\quad$ Speed

The 5th generation Wi-Fi is providing higher speed compared to the previous version of $802.11 \mathrm{n}$. The previous version maximum link rate was $450 \mathrm{Mbps}$, while $802.11 \mathrm{ac}$ is providing link rate up to $1.35 \mathrm{Gbps}$. In addition, such rate is maintained at any range and not like its predecessor where the rate was declining when the range increases.

This increase in speed is achieved by providing wider frequency bands, faster processing, and multiple antennas. Table (2) below, illustrates the speed difference between $802.11 \mathrm{ac}$ and $802.11 \mathrm{n}$. It is clear that $802.11 \mathrm{ac}$, will provide the same 3-antenna $802.11 \mathrm{n}$ system speed. In addition, power consumption for the systems still the same.

Table (2): Wireless Performance comparison between 802.11n and 802.11ac

\begin{tabular}{|c|c|c|}
\hline \multicolumn{3}{|c|}{ Wireless Performance Comparison } \\
\hline Antenna Configuration & $802.11 \mathrm{n}$ & $802.11 \mathrm{ac}$ \\
\hline $\begin{array}{r}\text { Single Stream (lxl) } 150 \\
\text { Mbps } 450 \mathrm{Mbp}\end{array}$ & Mbps 150 & $\mathrm{Mbp} 450$ \\
\hline $\begin{array}{r}\text { Dual Stream (2x2) } 300 \\
\text { Mbps } 900 \mathrm{Mbp}\end{array}$ & Mbps 300 & Mbp 900 \\
\hline Three Stream $(3 \times 3)$ & Three Stream $(3 \times 3)$ & Gbps 1.3 \\
\hline
\end{tabular}

\section{Reliability}

5G Wi-Fi provides higher capabilities for connection in term of coverage area and minimizing the effect of "dead spots". This is due to the feature of beam-forming which overcome the problems resulted from the building structure (i.e. Concrete walls,...etc).

Figure (2) below illustrates 802.11ac coverage and data rates compared with $802.11 \mathrm{n}$

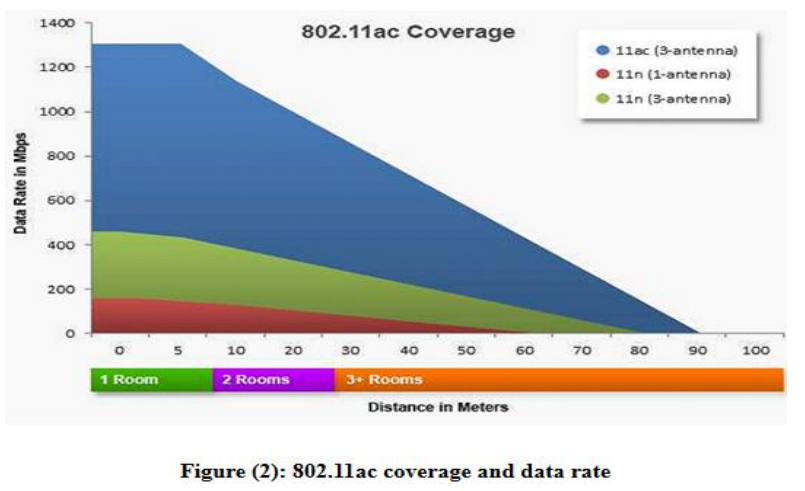

Wi-Fi 5th generation provides directional signal transmission and reception. Previous standards can only receive and transmit omnidirectional signals, which are subject to significant levels of interference, because the signals are transmitted indiscriminately in every possible direction. With beamforming, there's an understanding of the relative location of the device, and the signal is correspondingly strengthened in that direction. Figure (3) below indicate in a rough way the differences in connection approach and methodology for new Wi-Fi (using beamforming technology) compared to the predecessor one.

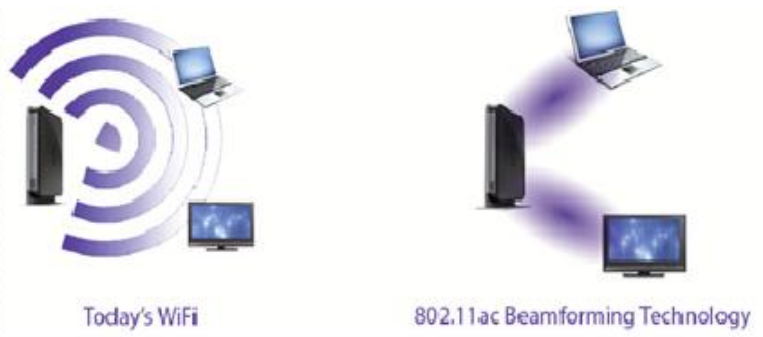

Figure (3): 802.11 ac and 802.11n differences in connection approach and methodology

\section{Quality}

In addition to its increased capacity and range, the $802.11 \mathrm{ac}$ standard operates in the $5 \mathrm{ghz}$ wireless spectrum, which is less prone to interference. Though more widespread in usage (all $802.11 \mathrm{~b}$ and $\mathrm{g}$ devices operate exclusively in the $2.4 \mathrm{ghz}$ spectrum), $2.4 \mathrm{ghz}$ only has three non-overlapping channels for transmission, which are crowded due to the vast number of interfering devices, including other wifi access points, microwave ovens, cordless phones, Bluetooth devices, and baby monitors. As a result, the environment is noisy, which increases interference and degrades performance. 
In contrast, the $5 \mathrm{ghz}$ channel is much cleaner with less interference, with 23 non-overlapping channels -8 times more than what is available in the $2.4 \mathrm{ghz}$ spectrum - which makes it far more suitable for applications such as video streaming and gaming, which are very sensitive to packet loss and delays.

Table (2) below illustrates the main two differences between the $2.4 \mathrm{ghz}$ wifi band and $5 \mathrm{ghz}$ Wi-Fi band.

Finally, the main advantages of 802.11ac are:

1. Speed is three times higher, compared to the predecessor technology.

2. Minimal dead spots allowing for enhanced performance.

3. Beamforming allows for reliable streaming and connection.

4. Higher mobile bandwidth

5. Using the $5 \mathrm{ghz}$ allows for lower noise connection.

6 .Compatible with 802.11 a \& $\mathrm{n}$.

Table (3): Differences between 802.11n and 802.11ac bands

\begin{tabular}{|c|c|}
\hline $\begin{array}{l}\text { 2.4ghz Band } \\
\text { (802.1ln) }\end{array}$ & $\begin{array}{l}\text { 5ghz Band } \\
\text { (802.1lac) }\end{array}$ \\
\hline More widespread usage & Less interface \\
\hline High interface & $8 \mathrm{x}$ more channels than $2.4 \mathrm{ghz}$ \\
\hline $\begin{array}{r}\text { Minimum WLAN feature required for } \\
\text { connectivity }\end{array}$ & Ideal for video streaming and gaming \\
\hline
\end{tabular}

\section{DETAILS OF 5G WI-FI}

For 802.11ac, the maximum throughput might reach 4900Mbps at $16 \mathrm{mhz}$ bandwidth (for Wave 2) while $2400 \mathrm{Mbps}$ at $80 \mathrm{mhz}$ bandwidth (for Wave 1).

Both waves are providing 8 spatial streams and the modulation technique is 256qamr5/6. Figure 4 below illustrates the major physical layer specifications for both wave 1 and 2 .

\begin{tabular}{|c|c|c|c|c|c|c|}
\hline Nominal Conflguration & Bandwdth (MHz) & $\begin{array}{l}\text { Number of } \\
\text { Spatial Stroms }\end{array}$ & $\begin{array}{l}\text { Constollation } \\
\text { Stza and Rato }\end{array}$ & Guard Intonal & $\begin{array}{l}\text { PHY Data Rato } \\
\text { (Mbps) }\end{array}$ & $\begin{array}{l}\text { Throughput } \\
\text { (Mbps)" }\end{array}$ \\
\hline Amendment max & 40 & 4 & G4QAMI516 & Short & 600 & 420 \\
\hline \multicolumn{7}{|l|}{ 802.11ac wave 1} \\
\hline Min & 80 & 1 & GAOAMI5/B & Long & 293 & 210 \\
\hline Low-ond product & 80 & 1 & Z260AMr516 & Short & 433 & 300 \\
\hline Midtier product & 80 & 2 & 2560AMr5/6 & Short & 867 & 610 \\
\hline High-end product & $\infty 0$ & 3 & 256QAMr5/6 & Short & 1300 & 910 \\
\hline $\begin{array}{l}80 \text { MHz amendment } \\
\max \end{array}$ & 80 & 8 & Z260AM156 & Short & 3470 & 2400 \\
\hline \multicolumn{7}{|l|}{ 802.11ac wave 2} \\
\hline Low-end product & 160 & 1 & Z6QAMI516 & Short & 867 & 610 \\
\hline Midtier product & 160 & 2 & ZSBCAMIS5/6 & Short & 1730 & 1200 \\
\hline High-end product & 160 & 3 & 2360AMI5/6 & Shont & 2000 & 1800 \\
\hline Ultra-high-end product & 160 & 4 & 2660AMr516 & Short & 3470 & 2400 \\
\hline Amendment max & 160 & 8 & 360AM15:6 & Short & $\cos 0$ & 4900 \\
\hline \multicolumn{7}{|c|}{$\begin{array}{l}\text { "Assuming a } 70 \% \text { efficient MAC, except to } 802.11 \text {, which lacks agregation. } \\
\text { "Assuming } 40 \mathrm{MHz} \text { is not avaliable due to the presence of oher APs. }\end{array}$} \\
\hline
\end{tabular}

802.11ac coverage and data rate 802.11ac has introduced new capability for MIMO which is called Multi-user MIMO (MU-MIMO) allowing for multiple streams to multiple clients increasing the total bandwidth that can be transmitted at the same time. Figure (5) illustrates the difference between the single MIMO (for 802.11n) and the multiple MIMO related 802.11ac.

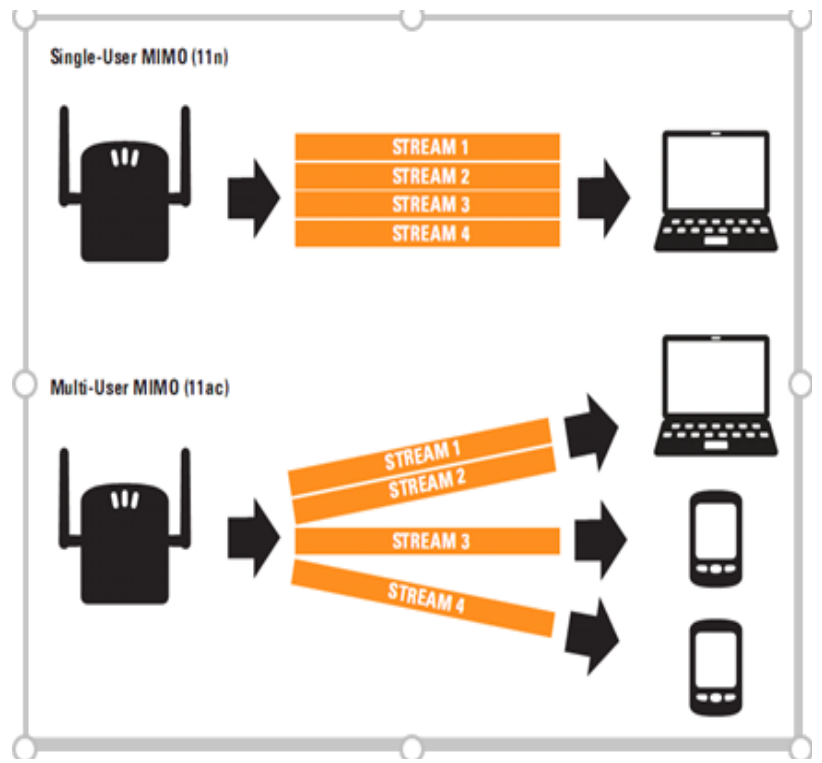

Figure (5): SU-MIMO Vs. MU-MIMO

\section{NEW WI-FI ROUTER SPECIFICATIONS}

IEEE 802.11ac is wireless computer network with standard 802.11.it is made by Wi-Fi brand name developed in IEEE standard Associations. It provides high bandwidth of wireless local area network (WLAN) with 5GHz. This standard was developed from 2011 thought 2013and approved in January 2014.

IEEE 802.11ac router supports dual band $(2.4 \mathrm{GHz}+5 \mathrm{GHz})$ simultaneous and it can give you speed up to $450 \mathrm{Mbps}+1300 \mathrm{Mbps}$. It is also known as "cloud router". It can access router via android or iOS settings.

The $802.11 \mathrm{ac} \mathrm{Wi}-\mathrm{Fi}$ standard is the latest in market and offers the speed up to $1300 \mathrm{Mbps}$ (1.3Gbps) of wireless connections. This router makes the capability comes with wireless $\mathrm{N}$ (Wi-Fi N or 802.11n) and it supports all existing Wi-Fi clients. Wi-Fi technology is used with fastest bandwidth of network.

Few years ago, the standard of Wi-Fi technology has been created in version $802.11 \mathrm{n}$, that is a wireless transmission protocol. It can send the data up to 600Mbps.but in new technology of Wi-Fi can send the data up to $1300 \mathrm{Mbps}$. In the Ac router technology we can use multiple inputs and multiple outputs in concurrently mode.

There are so many features in the 802.11ac router (AC router), which is useful for wireless communications.

1. 80MH Extended channel binding with bandwidth.

2. Eight spatial streams. 
3. Multiuser-MIMO (MU-MIMO) - each with one or more antennas, transmits or receive data stream concurrently.

4. Multiple access streams not speared by frequency.

5. $256 \mathrm{QMM}$, rate $3 / 4$, and 5/6 added s optional.

6. Beam forming with standard sounds for capability between vendors

7. MAC Modifications

8. $800 \mathrm{~ns}$ regular guard interval

9. Single spatial streams

\section{CONCLUSION}

802.11ac, which is known as the 5th generation of Wi-Fi technology, will be providing a data rates 3 times minimum of the $802.11 \mathrm{n} .802 .11 \mathrm{ac}$ will be backward compatible with the earliest technologies of the Wi-Fi but with improved reliability, throughput and range. By 2015, it is expected that all products will be based on 802.11 ac technology.

802.11ac will provide new hub for video streaming and gaming. The bandwidth provided by the new technology allows for HD video streaming without choppy playback. Gaming had become an increasing demand for many users, where wireless connection between game consoles (such as PS4) is required to maintain online gaming experience.

Smart phones and tablets will get advantage of this new technology. Current situation has many frustrations in poor connection. The new Wi-Fi technology solves the current problem allowing for enhanced, high speed and reliable connection.

In addition to meeting today's growing needs such as streaming video, the new standard will also enable a variety of new use cases such as simultaneous HD video streams to multiple receivers, wireless displays, and large file wireless transfers. It's also better equipped to handle the seemingly boundless growth in the number and type of wifi devices (even many appliances are becoming wifi equipped) as well as the corresponding traffic that comes with that growth. In short, 802.11ac will have the capability to handle our insatiable demand for robust, high-speed connectivity from a wide range of devices.

\section{REFERENCES}

[1] R. Baldemair; E. Dahlman; G. Fodor; G. Mildh; S. Parkvall; Y. Selen; H. Tullberg; K. Balachandran (March 2013). .1109/MVT.2012.2234051""Evolving Wireless Communications: Addressing the Challenges and Expectations of the Future". IEEE Vehicular Technology Magazine, vol. 8, no. 1. Ericsson Research. Pp. 24-30. Retrieved 27 September 2013

[2] Md. Alimul Haque, Pritam Kumar, Amrendra Kumar Singh, 2012, "IEEE 802.11ac: 5th Generation wifi Networking", World Applied Programming, Vol (2), No (4), April 2012. 235-241, WAP journal. Http://www.waprogramming.com/

[3] Motorola Solutions 2012, "What you need to know about 802.11ac", white paper, July 2012, http://www.motorolasolutions.com

[4] CISCO, 802.11ac: "the fifth generation of Wi-Fi", Technical white paper, August 2012, http://www.waprogramming.com/

[5] NETGEAR, Next Generation Gigabit wifi - 802.11ac, 2012, whitepaper,www.netgear.com.http://www.ieice.org/eng/shiori/mok uji.html 